\title{
Effect of Surface Roughness on Amalgam Repair Using Adhesive Systems
}

\author{
Marcelo GIANNINI ${ }^{1}$ \\ Luis Alexandre Maffei Sartini PAULILLO \\ Gláucia Maria Bovi AMBROSANO2 \\ ${ }^{1}$ Department of Restorative Dentistry, ${ }^{2}$ Department of Social Dentistry, \\ Piracicaba School of Dentistry, UNICAMP, Piracicaba, SP, Brazil
}

\begin{abstract}
The objective of this in vitro study was to evaluate the effect of three surface treatments and two adhesive systems on the shear bond strength of old and freshly placed amalgam. The results suggested that the intact amalgam showed a significantly higher strength than repaired groups and the strongest repaired specimens were made when the amalgam surfaces were roughened with a diamond bur or microetcher. The adhesive systems showed no significant differences on bond strength with the same superficial texture.
\end{abstract}

Key Words: amalgam repair, high-copper admixed alloy, adhesive system, sandblaster, bond strength.

\section{INTRODUCTION}

Defective dental amalgam restorations are usually treated by replacement with new amalgam or other restorative materials, causing dentists to spend about half their chair time replacing restorations (1). As a viable conservative technique, the repair of defective areas has been suggested because it is simple and quick (2-4). Repair also preserves the tooth, as it is difficult to remove a restoration without removing an integral part of the tooth itself (5). Mondelli et al. (6) and Berry et al. (5) reported that the smaller the restoration, the stronger the tooth, thus, if unnecessary sound enamel and dentin removal is avoided, strength is maintained and longevity of the tooth is increased.

In most studies, the interface between old and freshly condensed amalgam shows low bond strength. Repaired amalgam specimens subjected to flexural strength tests were less than half that of intact amalgam (7-9). To increase the bond strength between old and fresh amalgam, it has been suggested to roughen the old amalgam surface (8) or to condense the fresh amalgam with an excess of mercury $(7,10)$. Other studies have indicated that a bond to freshly condensed amalgam is significantly greater than that to an older one $(7,11)$.
However, Walker Jr and Reese (8) and Jorgensen and Saito (10) reported that the age of the amalgam does not interfere with bond strength. Clinically, because of low bond strength, researchers have recommended the addition of mechanical retentive features, either into the tooth structure or existing amalgam, to increase the performance of repaired amalgam restorations $(3,4,7,8)$.

Adhesive systems can be used as resin liner in bonded amalgam restorations (12). The use of these adhesives has also been suggested for repairing amalgam restorations associated with the roughening of an old amalgam surface (9,13-16). The application of an adhesive system could improve bonding between old and new amalgam through mechanical interlocking between the adhesive system and freshly condensed amalgam $(12,15)$. The irregular surfaces are micromechanical retentions for bonding of primer to old amalgam and can be created with a carbide bur, diamond bur or aluminum oxide particle abrasion (1517).

Thus, the purpose of the present study was to evaluate the shear bond strength of intact amalgam and amalgam repaired using adhesive systems associated or not with surface treatments of the old amalgam, simulating an amalgam repair. 


\section{MATERIAL AND METHODS}

To determine the shear bond strength of repaired high-copper amalgam and intact amalgam, two adhesive systems (Scotchbond Multipurpose Plus, 3M Dental Products, St. Paul, MN, USA and All Bond 2, Bisco Inc., Itasca, IL, USA), a high-copper admixed amalgam alloy (Permite C, Southern Dental Industries, Bayswater, Vic, Australia), a diamond bur (1014 - KG Sorensen, Barueri, SP, Brazil) and a microetcher (Danville Engineering Inc., San Ramon, CA, USA) were selected. See Table 1 for the composition of these materials.

Seven experimental groups were evaluated, six containing repaired amalgam and one containing intact amalgam, using 10 repetitions for each group. The specimens were prepared using precapsulated admixed alloy, and were activated and triturated in a high-speed amalgamator (Ultramat 2, Southern Dental Industries) for $8 \mathrm{~s}$ and then manually condensed into molds, using a round-faced condenser (Ward \#2 - Duflex, SS White

Table 1. Composition of materials used in the study.

\begin{tabular}{|c|c|}
\hline Material & Composition \\
\hline Permite C & $\begin{array}{l}\text { High copper (15.4\%) admixed amalgam } \\
\text { alloy }\end{array}$ \\
\hline Scotchbond & Activator: Sulphinic acid salt \\
\hline Multipurpose Plus & $\begin{array}{l}\text { Primer: Aqueous solution of HEMA and } \\
\text { polyalcenoic acid copolymers } \\
\text { Adhesive: Solution of Bis-GMA }(62.5 \%) \\
\text { and HEMA }(37.5 \%) \text { and combination of } \\
\text { amines } \\
\text { Catalyst: HEMA, Bis-GMA and benzoyl } \\
\text { peroxide }\end{array}$ \\
\hline All Bond 2 & $\begin{array}{l}\text { Primer A: NTG-GMA } 2 \% \\
\text { Primer B: BPDM 16\% } \\
\text { Adhesive: Bis-GMA, UDMA and HEMA } \\
\text { Pre-Bond: Bis-GMA, TEGDMA, HEMA } \\
\text { and benzoyl peroxide }\end{array}$ \\
\hline Microetcher & Aluminum oxide $(50 \mu \mathrm{m})$ particle abrasion \\
\hline 1014 Diamond Bur & $\begin{array}{l}\text { Natural diamond (average granulometry - } \\
90 \text { to } 120 \mu \mathrm{m} \text { ) }\end{array}$ \\
\hline
\end{tabular}

HEMA - 2-hydroxyethyl methacrylate; Bis-GMA - bisphenol glycidyl methacrylate; NTG-GMA - N-tolylglycine glycidyl methacrylate; BPDM - biphenyl dimethacrylate; UDMA urethane dimethacrylate; TEGDMA - triethylene glycol dimethacrylate.
Art. Dent. Ltda, Rio de Janeiro, RJ, Brazil).

Intact amalgam group (control group): A cavity preparation ( $7 \mathrm{~mm}$ diameter by $2 \mathrm{~mm}$ high) was made in the ten self-curing polyester resin cylinders $(2.7 \mathrm{~cm}$ diameter by $2.0 \mathrm{~cm}$ high) (Figure 1a). The amalgam was condensed into the cavity until it was slightly overfilled (Figure 1b), and it was then carved level with the polyester resin surface. Each specimen was immediately secured in a Teflon split mold to serve as a matrix for amalgam placement. The Teflon mold upper aspect contained an opening of $3 \mathrm{~mm}$ diameter x $5 \mathrm{~mm}$ high. The amalgam was condensed through this opening (Figure 1c). The split mold was removed $1 \mathrm{~h}$ after condensation, thus providing a $3 \mathrm{~mm}$ diameter $\mathrm{x} 5 \mathrm{~mm}$ high amalgam cylinder over the base amalgam of $7 \mathrm{~mm}$ diameter $\mathrm{x} 2 \mathrm{~mm}$ high (Figure 1d). The intact amalgam specimens were stored at $100 \%$ relative humidity for 37 days at $37^{\circ} \mathrm{C}$.

Repaired amalgam groups: The same cavity preparation (7 $\mathrm{mm}$ diameter $\mathrm{x} 2 \mathrm{~mm}$ high) for intact specimens was made in the sixty self-curing polyester resin cylinders $(2.7 \mathrm{~cm}$ diameter x $2.0 \mathrm{~cm}$ high) (Figure 1a). The amalgam was condensed into the cavity until it was slightly overfilled (Figure 1b), then carved level with the polyester resin surface. After aging of all samples in $100 \%$ relative humidity at $37^{\circ} \mathrm{C}$ for 30 days, the amalgam surfaces were polished with a finishing carbide bur (12 blades, Maillefer, Ballaigues, Switzerland) and abrasive rubber cups (KG Sorensen, Barueri, SP, Brazil). Groups G2 and G3 were not treated after polishing the amalgam surfaces. In groups G4 and G5,

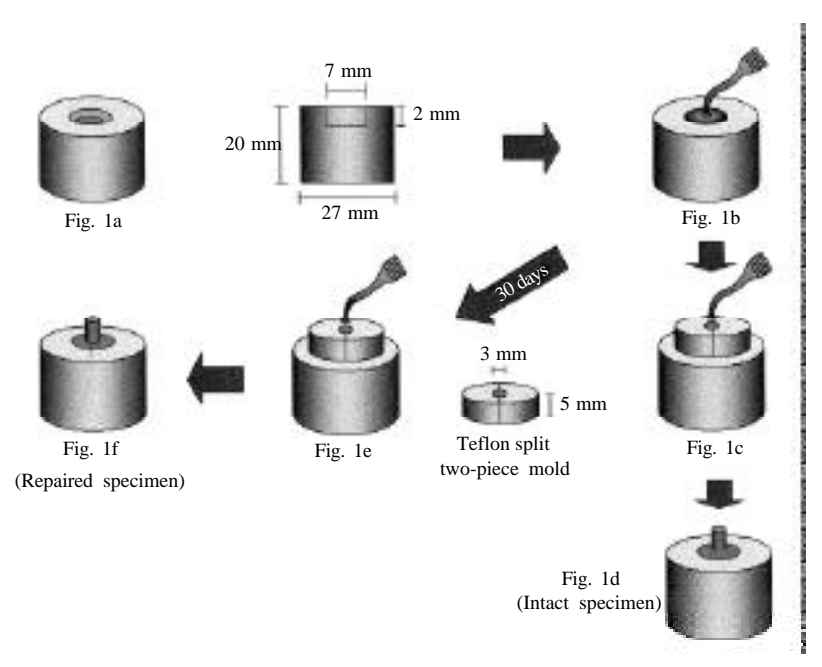

Figure 1. Schematic representation of methodology used to prepare specimens. 
the polished amalgam surfaces were sandblasted with aluminum oxide particle abrasion for $10 \mathrm{~s}$, and in groups G6 and G7, the polished amalgam surfaces were roughened with a 1014 high-speed diamond bur, also for $10 \mathrm{~s}$. A circular area, $3 \mathrm{~mm}$ diameter, was defined on the amalgam surface using a hole punched in PVC selfadhesive tape. Scotchbond Multipurpose Plus adhesive system was applied in groups G2, G4 and G6, while the All Bond 2 adhesive system was applied in groups G3, G5 and G7, both according to manufacturer instructions (Table 2). The opening of the two-piece Teflon mold ( $3 \mathrm{~mm}$ diameter and $5 \mathrm{~mm}$ high) was fixed on the demarcated bonding area of the amalgam surface. The fresh amalgam was transferred to the opening and was condensed firmly against the amalgam treated surface (Figure 1e). After $1 \mathrm{~h}$, the two-piece Teflon mold was removed to expose the cylinder of amalgam freshly bonded to the previously placed amalgam (Figure 1f). The samples were stored in $100 \%$ relative humidity at $37^{\circ} \mathrm{C}$ for 1 week prior to testing.

Shear bond strength test: Each test sample was locked into a special device, which was seated on the compression load cell of a universal testing machine (DL 500, Emic, São José dos Pinhais, PR, Brazil). A shear load was applied to the base of the amalgam cylinder with a knife-edge rod with a width of $0.5 \mathrm{~mm}$ at a crosshead speed of $0.5 \mathrm{~mm} / \mathrm{min}$. The shear bond strengths were calculated and expressed in MPa. The

Table 2. Manufacturer instructions for bonding fresh amalgam to old amalgam.

\section{Scotchbond Multipurpose Plus}

- Apply Activator to all amalgam surfaces. Dry the Activator with a gentle air stream for $5 \mathrm{~s}$. Do not rinse off the Activator.

- Apply Primer to activated surfaces. Dry the Primer with a gentle air stream for $5 \mathrm{~s}$. Do not rinse off the Primer.

- Mix one drop each of Adhesive and Catalyst. Apply the mixed adhesive to the primed surfaces.

- Condense amalgam.

\footnotetext{
All Bond 2

- Mix Primer A and B. Apply two coats. Dry for 5-6 s with an air syringe to ensure thorough solvent removal.

- Mix an equal amount of Dentin/Enamel Bonding Resin and Pre-Bond on a mixing pad and brush a thin layer onto the surface. Lightly air thin to prevent pooling.

- Condense amalgam.
}

results were analyzed statistically by two-way analysis of variance (ANOVA), Dunnett's test and Tukey test at the $5 \%$ level of significance.

Scanning electron microscopy: The following materials were prepared and analyzed with a scanning electron microscope (DSM 940A, Zeiss, Oberkochen, Germany): representative samples of the amalgam surface polished with a finishing carbide bur and abrasive rubber cups, the amalgam surface microetched with aluminum oxide for $10 \mathrm{~s}$ and the amalgam surface roughened with a 1014 diamond bur for $10 \mathrm{~s}$.

\section{RESULTS}

Table 3 shows the mean shear bond strengths and standard deviations for the control and experimental treatment groups. ANOVA revealed a statistically significant difference among groups $(\mathrm{p}<0.05)$, thus the data were analyzed further using Dunnett's and Tukey tests. Dunnett's test indicated that the shear bond strengths of all repaired groups were lower than intact amalgam $(\mathrm{p}<0.05)$. The analysis of the data by Tukey test showed that the strongest repaired specimens were made when the amalgam surface was roughened with a diamond bur or microetcher $(\mathrm{p}<0.05)$.

All specimens from the repaired groups failed adhesively between the old and the fresh amalgam. Figure 2 shows the amalgam surface polished with a finishing carbide bur (12 blades) and abrasive rubber cups, and Figures 3 and 4 show the different roughness patterns created by microetching for $10 \mathrm{~s}$ and 1014

Table 3. Mean and standard deviation of shear bond strength in test groups $(\mathrm{MPa} \pm \mathrm{SD})$.

\begin{tabular}{|c|c|c|}
\hline \multirow[t]{2}{*}{ Surface Treatment } & \multicolumn{2}{|c|}{ Adhesive System } \\
\hline & SBMP-Plus & All Bond 2 \\
\hline No roughness & (G2) $3.35 \pm 0.91 \mathrm{bA}$ & (G3) $3.15 \pm 1.60 \mathrm{~b}$ \\
\hline Microetching & (G4) $5.30 \pm 1.95 \mathrm{aA}$ & (G5) $5.34 \pm 1.85 \mathrm{aA}$ \\
\hline 1014 diamond bur & (G6) $5.45 \pm 2.03 \mathrm{aA}$ & (G7) $5.57 \pm 2.16 \mathrm{a}$ \\
\hline
\end{tabular}

Control group (G1 - intact amalgam): $18.82 \pm 5.97$

Coefficient of variation $=28.04 \%$

All groups were significantly different from the control group (intact amalgam) by Dunnett's test $(\mathrm{p}<0.05)$. Means followed by different letters (lower case - column and capital letter - line) were significantly different by Tukey test $(\mathrm{p}<0.05)$. 


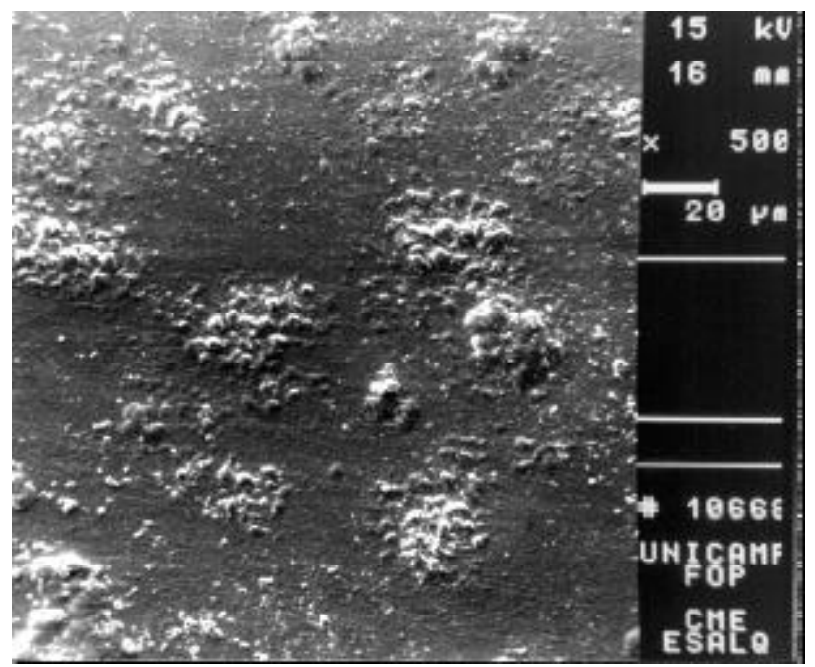

Figure 2. Aspect of amalgam surface polished with finishing carbide bur (12 blades) and abrasive rubber cups. Original magnification, 500X.

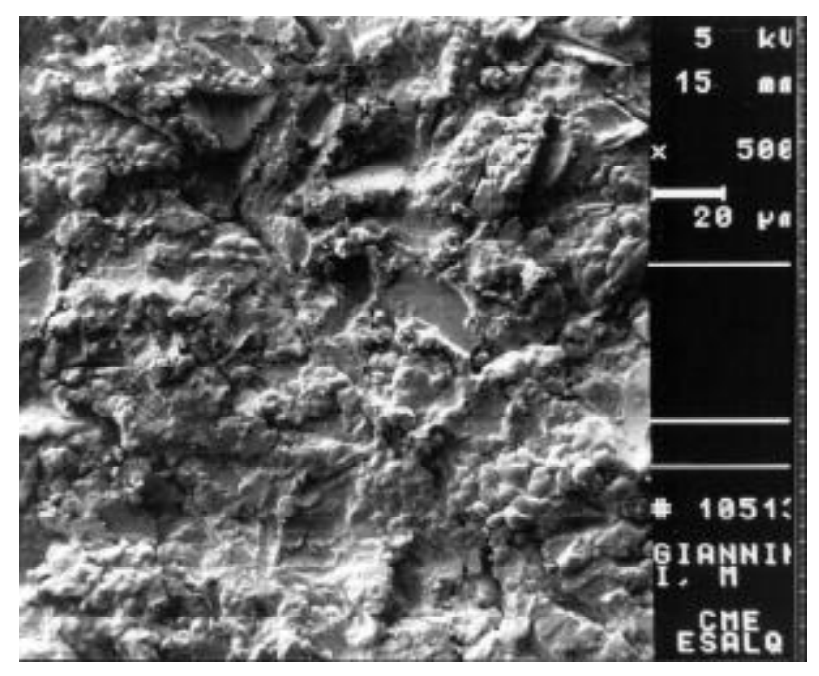

Figure 3. Aspect of amalgam surface microetched with $50 \mu \mathrm{m}$ aluminum oxide particle abrasion for $10 \mathrm{~s}$. Original magnification, 500X.

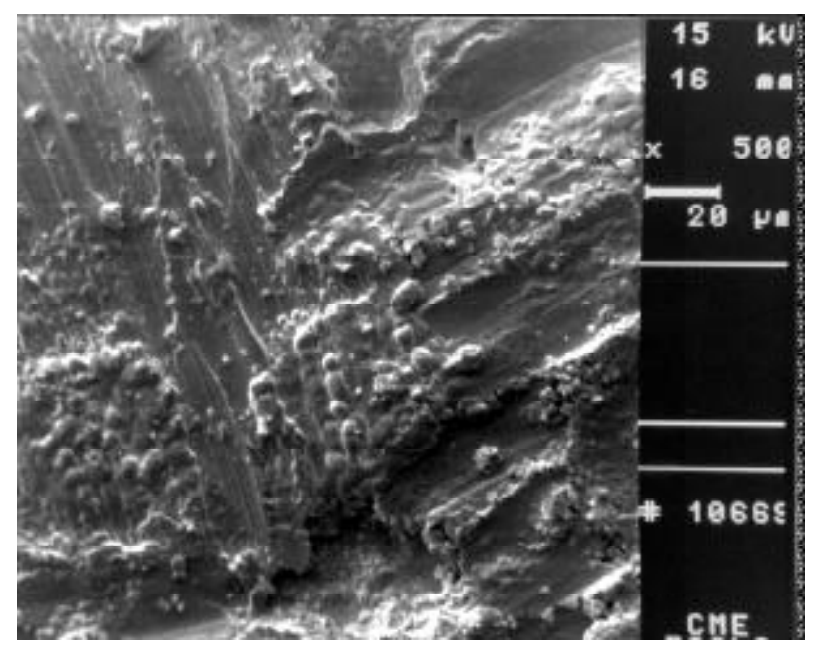

Figure 4. Aspect of amalgam surface roughened with 1014 diamond bur for $10 \mathrm{~s}$. Original magnification, $500 \mathrm{X}$. diamond bur for $10 \mathrm{~s}$, respectively. Roughness was created on the old amalgam surface by aluminum oxide particle abrasion (Figure 3) and traces of diamond grain were observed when the old amalgam surface was roughened with 1014 diamond bur (Figure 4).

\section{DISCUSSION}

The importance of conservative procedures has justified the clinical application of amalgam repair (26 ) in spite of in vitro studies that report low bond strength of new amalgam condensed against previously set amalgam $(7-9,14,15,17)$, since the quality of an amalgam-to-amalgam restorative interface cannot be only measured by shear bond strength (16). For lack of bonding to old amalgam, enamel and dentin, undercuts as grooves, dovetail and pins may be added to provide adequate retention to the repaired areas $(3,4,7,8,15)$. In this laboratory study, three different superficial textures of old amalgam were tested: polished, roughened with a 1014 diamond bur and microetched, and two adhesive systems, All Bond 2 and Scotchbond Multipurpose Plus, in an attempt to enhance the bond strength of amalgam repairs.

From the use of 4-META (4-methacryloxyethyl trimellitate anhydride)-based adhesive systems to bond fresh amalgam to an old amalgam restoration (13-15), other monomers have also been suggested to repair amalgam $(9,16,18)$. The 4-META monomer has the ability to react with metals through the formation of ionic bonds with formed metallic oxides or with the active metal components of the amalgam. Nevertheless, the bonded repair specimens did not recover the strength of intact specimens (14). According to manufacturer instructions, Scotchbond Multipurpose Plus and All Bond 2 are indicated for amalgam repair, although there were no reports that their monomers, HEMA, BPDM and NTG-GMA, promoted a bond to amalgam.

The investigation of bond strength of a repaired amalgam restoration is shown in several studies in which the strength of repaired amalgams approaches that of intact amalgam $(10,19,20)$. Similar to most of the investigations, the mean shear bond strength of the control group was higher than the strength of repaired amalgam groups in this study. Neither superficial treatment to roughen old amalgam nor chemical adhesives insured similar bond strength when compared to intact 
amalgam. Other studies that used high-copper spherical or admixed alloy reported results of flexural bond strength of 100 to $180 \mathrm{MPa}(8,10,15)$ and shear bond strength of 12 to $25 \mathrm{MPa}(14,16)$. The amalgam used in this study was a high-copper (15.4\%) alloy and the mean shear bond strength of intact amalgam was 18.82 $\pm 5.97 \mathrm{MPa}$.

The data analyzed among repaired amalgam groups indicated that with the same superficial texture, polished, microetched and roughened with diamond bur, the adhesive systems, All Bond 2 and Scotchbond Multipurpose Plus, showed no significant differences of bond strength. When the old amalgam surface was roughened with a 1014 diamond bur or microetched prior to application of the adhesive, the bond strength was higher than when the old amalgam surface was polished and without roughness. This increase can be attributed to the roughness of the old amalgam surface, because roughness provided micromechanical retentions and increased the superficial area of the adhesive system. Although roughness created with the 1014 diamond bur and the microetching has different superficial morphology patterns, there were no significant differences between the diamond bur and microetching on bond strength.

The results of the present study show that roughening an old amalgam surface is an essential step when adhesive systems are used to repair amalgam restorations and the simple use of a diamond bur can roughen old amalgam.

\section{ACKNOWLEDGMENTS}

This study was supported by FAEP-UNICAMP (grant 1010/96). The authors are indebted to Prof. E. W. Kitajima (NAP-MEPA/ESALQ-USP).

\section{RESUMO}

Giannini M, Paulillo LAMS, Ambrosano GMB. Efeito da rugosidade superficial no reparo em amálgama utilizando sistemas adesivos. Braz Dent J 2002;13(3):179-183.

O objetivo deste estudo foi avaliar o efeito de três tratamentos superficiais e dois sistemas adesivos na resistência ao cisalhamento de reparos em amálgama. Os resultados sugerem que os grupos reparados não apresentaram resistência de união semelhante ao amálgama intacto. Entre os grupos reparados com sistemas adesivos, valores superiores de resistência de união foram observados para os grupos que tiveram a superficie abrasionada com ponta diamanatada ou jateada. Os sistemas adesivos não apresentaram diferenças significativas na resistência ao cisalhamento quando comparados no mesmo tratamento superfical do amálgama.

Unitermos: reparo em amálgama, liga do tipo mistura de alto conteúdo de cobre, sistema adesivo, jateamento, resistência de união.

\section{REFERENCES}

1. Going R, Jendreson M. Failure related to materials used in restorative dentistry. Dent Clin North Am 1972;16:71-86.

2. Penning C. Repair and revision 1. Repair or replacement of amalgam. Ned Tijdschr Tandheelkd 2001;108:46-49.

3. Cowan RD. Amalgam repair - A clinical technique. J Prosthet Dent 1983;49:49-51.

4. Baratieri LN, Monteiro Jr S, Andrada MAC. Amalgam repair: a case report. Quintessence Inter 1992;23:527-531.

5. Berry TG, Laswell HR, Osborne JW, Gale EN. Width of isthmus and marginal failure of restorations of amalgam. Oper Dent 1981;6:55-58

6. Mondelli J, Steagall L, Ishikiriama A, Navarro MFL, Soares FB. Fracture strength of human teeth with cavity preparations. J Prosthet Dent 1980;47:419-422.

7. Terkla LG, Mahler DB, Mitchen JC. Bond strength of repaired amalgam. J Prosthet Dent 1961;11:942-947.

8. Walker Jr AC, Reese SB. Bond strength of amalgam to amalgam in a high-copper amalgam. Oper Dent 1983;8:99-102.

9. Fruits TJ, Duncanson MG, Coury TL. Interfacial bond strength of amalgam bonded to amalgam and resin composite bonded to amalgam. Quintessence Inter 1998;29:327-334.

10. Jorgensen KD, Saito T. Bond strength of repaired amalgam. Acta Odontol Scand 960;26:605-615.

11. Scott GL, Grisius RJ. Bond strength at the interface of new and old spherical amalgam. US Navy Med News Letter 1969;54:34.

12. Swift Jr EJ, Perdigão J, Heymann HO. Bonding to enamel and dentin. A brief history and state of the art, 1995. Quintessence Inter 1995;23:53-59.

13. Roeder LB, DeSchepper EJ, Powers JM. In vitro bond strength of repaired amalgam with adhesive bonding systems. J Esthet Dent 1991;3:126-132.

14. Chang J, Scherer W, Tauk A, Martini R. Shear bond strength of a 4-META adhesive system. J Prosthet Dent 1992;67:42-45.

15. Lacy AM, Rupprecht R, Watanabe L. Use of self-curing composite resins to facilitate amalgam repair. Quintessence Inter 1992;23:53-59.

16. Diefenderfer KE, Reinhardt JW, Brown SB. Surface treatment effects on amalgam repair strength. Am J Dent 1997;10:9-14.

17. Jessup JP, Vandewalle KS, Hermesh CB, Buikema DJ. Effects of surface treatments on amalgam repair. Oper Dent 1998;23:15-20.

18. Unlu OF, Ozturk B, Sengun A. Amalgam repair: evaluation of bond strength and microleakage. Oper Dent 2002;27:199-203.

19. Fukuba S, Hiraoka H, Shimasue K, Shintani H, Jnoue T. Studies on the repaired fill-using dispersed phase amalgam. Hiroshima Daigaka Shigakuk Zasshi 1977;9:25-32.

20. Kirk EEJ. Amalgam to amalgam bond: a preliminary report. Dent Pract 1962;12:371-372.

Accepted May 15, 2002 